\title{
La percepción de los debates como factor de decisión en el comportamiento electoral en las Elecciones Generales de abril de 2019
}

\section{The Perception of the Debates as a Decision Factor in Electoral Behavior in the General Elections of April 2019}

\author{
Nieves Lagares Diez. Universidad de Santiago de Compostela. España. \\ mnieves.lagares@usc.es \\ [CV] (D) \\ Erika Jaráiz Gulías. Universidad de Santiago de Compostela. España. \\ erika.jaraiz@usc.es \\ $[\underline{\mathrm{CV}}]$ C \\ Paloma Castro Martínez. Universidad de Santiago de Compostela. España. \\ paloma.castro2@usc.es
}

$[\underline{\mathrm{CV}}]$ (C)

\begin{abstract}
Cómo citar este artículo / Referencia normalizada
Lagares Diez, N., Jaráiz Gulías, E. y Castro Martínez, P. (2020). La percepción de los debates como factor de decisión en el comportamiento electoral en las Elecciones Generales de abril de 2019. Revista Latina de Comunicación Social, (76), 39-58. https://www.doi.org/10.4185/RLCS$\underline{2020-1436}$
\end{abstract}

\section{RESUMEN}

Introducción: En el presente trabajo se analizan los efectos de los debates electorales sobre las percepciones de los ciudadanos acerca de los candidatos y sobre el voto a los principales partidos en las Elecciones Generales de abril de 2019. Metodología: Análisis descriptivo y modelos lineales generalizados con link logit para explicar el voto, mediante el empleo del Estudio $\mathrm{n}^{\mathbf{0}} 3248$ Postelectoral Elecciones Generales, 2019 elaborado por el Centro de Investigaciones Sociológicas (CIS). Resultados: Los modelos muestran que la percepción acerca de qué candidato resultó el más convincente en los debates electores influye significativamente en el voto. Discusión y conclusiones: Los debates electorales tienen un efecto principalmente de refuerzo tanto del voto como de los liderazgos de los participantes en estos.

PALABRAS CLAVE: debates electorales; comunicación política; comportamiento electoral; voto.

\begin{abstract}
Introduction: This paper analyses the effects of the electoral debates on citizens' perceptions about the candidates and on the vote for the main parties in the General Elections of April 2019. Methodology: Descriptive analysis and generalized linear models with link logit to explain the vote, through the use of the Post-Election Study No. 3248 of the General Elections, 2019 prepared by the Center for Sociological Research (CIS by its acronym in Spanish). Results: The models show that
\end{abstract}


the perception about which candidate was the most convincing in the electoral debates significantly influences the vote. Discussion and conclusions: Electoral debates have mainly a reinforcing effect on both the vote and the leadership of the participants in these.

KEYWORDS: electoral debates; political communication; electoral behavior; vote.

\section{CONTENIDOS}

1. Introducción. 2.1. Los debates electorales y sus efectos. 2.2. Los debates en la campaña de las Elecciones Generales de abril 2019: Un partido de ida y vuelta. 3. Metodología y datos. 4. Resultados. 5. Discusión y conclusiones. 6. Referencias bibliográficas.

\section{Introducción}

En las democracias de audiencia, tal y como las define Manin (2006), los debates electorales constituyen actos clave de las campañas electorales. La particularidad de estos eventos reside en el hecho de que la lógica tradicional de la campaña, que se basa en la relación entre candidatos y ciudadanos, es sustituida por la interacción directa de los candidatos (Castro et al., 2017). Se genera así, al mismo tiempo, la atención de una gran parte del electorado, llegando, al ser emitidos a través de los medios de comunicación de masas, generalmente en horarios de máxima audiencia; incluso a targets que, habitualmente, no son receptores de la información política (como es el caso de los votantes indecisos).

Si bien, los debates electorales no sólo son parte de la oferta informativa de los medios como resultado de la "mediatización" de las sociedades contemporáneas, sino que también responden a la demanda informativa de los ciudadanos. Estos últimos, en la búsqueda de sus recursos cognitivos, encuentran en los debates la oportunidad propicia para conocer a los candidatos, su oferta programática, sus posiciones políticas ante una serie de issues, así como su estilo y aptitudes. De hecho, para el público, los debates electorales pueden ser la única oportunidad para ver y juzgar a los candidatos en un contexto cara a cara (Schrott, 1990).

Los debates electorales resultan ser cruciales porque, aun asumiendo esta actitud activa del electorado, los individuos, como seres racionales, tratan de economizar los recursos (como, por ejemplo, el tiempo) destinados al conocimiento de la oferta política para la conformación de sus preferencias y posterior toma de decisiones relativas a la participación y orientación del voto (Downs, 1957). En este sentido, la traslación de la idea de los "atajos cognitivos" de la Escuela de Michigan al contexto de los debates electorales, hace que puedan ser concebidos como "atajos informativos" (Castro et al., 2017). Si la función básica de una campaña electoral es dotar de información, los debates electorales son una de las fuentes de información de la campaña electoral (Crespo et al., 2011), cumpliendo, además, a juicio de Best y Hubbard (1999), tres funciones normativas:

i. Los debates electorales involucran a los espectadores en la campaña: aumentan su implicación, animando a los electores a mostrar interés por los candidatos y por los temas que tratan, y su participación en la elección.

ii. Los debates electorales informan a los potenciales votantes de los temas: ponen en consideración la importancia de las diversas cuestiones políticas y las alternativas que se ofrecen como soluciones a éstas, permitiendo a los espectadores evaluar las agendas de temas y las posiciones políticas respecto a éstos de los distintos candidatos.

iii. Los debates electorales informan a la audiencia acerca de los líderes políticos: revelan las cualificaciones, los rasgos característicos y las posiciones políticas en torno a los temas sobre 
los que se debate, permitiendo a los espectadores evaluar a los candidatos y decidir la orientación de su voto.

Aun siendo estas las funciones de los debates electorales, el efecto principal que se le atribuyen es, además de un mayor conocimiento de los líderes políticos, el efecto de refuerzo del electorado, al margen de que puedan tener incidencia sobre los ciudadanos indecisos (Best y Hubbard, 1999; Yawn y Beatty, 2000; Sierra, 2012; Gallego y Bernárdez, 2017).

Así, el objetivo de este trabajo es el de averiguar si los debates electorales celebrados con motivo de las Elecciones Generales de abril de 2019 han influido en las percepciones que los ciudadanos tienen acerca de los principales líderes políticos que concurrieron en dichos comicios, y si, en última instancia, han tenido algún tipo de efecto sobre la decisión de voto a los partidos políticos.

\subsection{Los debates electorales y sus efectos}

Los debates electorales se han constituido como eventos fundamentales dentro del transcurso de las campañas electorales, desde su aparición en 1952 en Estados Unidos hasta su conversión en una institución típicamente estadounidense en 1976, años después de los famosos debates disputados entre Nixon y Kennedy (Jamieson y Birdsell, 1988). También en el caso de España, donde la Ley Orgánica del Régimen Electoral General (LOREG) no obliga a su realización, son un acontecimiento clave, pues desde el primer debate entre Felipe González y José María Aznar en 1993, y tras quince años sin debates electorales en Elecciones Generales, se llevan celebrando con continuidad en todas las campañas electorales nacionales desde el año 2008, cuando se disputó el cara a cara entre Mariano Rajoy y José Luis Rodríguez Zapatero.

No obstante, de los tradicionales cara a cara, en los últimos años, se ha pasado a la celebración de debates a cuatro, como consecuencia del aumento del pluralismo político causado por la incursión con fuerza de nuevos partidos políticos en la escena nacional, fundamentalmente Ciudadanos ( $\left.\mathrm{C}^{\prime} \mathrm{s}\right)$ y Unidas Podemos. Este aumento del número de partidos relevantes en el panorama estatal, y cuyos líderes, por tanto, participan en los debates, no sólo ha tenido consecuencias en los resultados electorales y en la posterior conformación de gobiernos, sino que también supone una dificultad añadida a la medición de los efectos que dichos debates pueden causar en el comportamiento político de los electores.

A este respeto, los estudios sobre debates electorales se pueden clasificar en dos grandes grupos (García, 2015): los trabajos que analizan la estructura y el contenido de los debates (Weiler, 1989; Benoit y Wells (1996); Benoit y Harthcock, 1999; Benoit y Brazeal, 2002; Herrero y Benoit, 2009) y las investigaciones que analizan los efectos de los debates sobre los espectadores (Abramowitz, 1978; Bishop et al., 1978; Schrott, 1990; Benoit, McKinney y Lance Holbert, 2001; Benoit, Hansen y Verser, 2003; Benoit et al., 2004; Cho y Ha, 2012).

En España, las investigaciones cuyo objetivo es el demostrar el impacto de los debates en los votantes, esto es, el conocimiento y evaluaciones de los participantes, el refuerzo y los cambios en las intenciones de voto, han sido escasamente desarrolladas (Herranz-Rubio, 2020), prueba de ellas son los trabajos de Lledó (2001), Luengo (2011) y Sierra (2012).

Por tanto, los efectos de los debates electorales, perspectiva en la que se enmarca el presente trabajo, pueden ser de carácter actitudinal, es decir, el modo en que los debates electorales pueden condicionar las percepciones y las valoraciones de los ciudadanos hacia los líderes políticos; o efectos de comportamiento, la forma en que los debates electorales pueden afectar a la decisión de voto de los electores (Lledó, 2001). 
Sin embargo, se observa una falta de consenso entre los trabajos precedentes. Por un lado, a pesar de que los debates televisados tienen la capacidad de llegar a una gran parte de la población (así lo demuestran los índices de audiencia), generalmente, sólo son vistos por aquellas personas que ya manifiestan un gran interés por la política y, por consiguiente, son las más informadas. De acuerdo con el modelo de efectos limitados, según el cual, las campañas electorales tienen un efecto mínimo en el resultado de las elecciones (Barreiro et al., 2015), los debates electorales no tendrían ningún tipo de efecto más allá del refuerzo de las predisposiciones de los votantes, ya que los individuos se muestran reticentes a asimilar nuevas informaciones, sobre todo, si son discordantes con los conocimientos precedentes, a fin de mantener una coherencia cognitiva (Lledó, 2001). Al contrario, otras investigaciones defienden la existencia de cierta influencia de los debates electorales sobre la decisión de voto de los ciudadanos (Geer, 1988; Schrott, 1990; Shelley y Hwang, 1991; Lanoue, 1992; Holbrook, 1994 y 1996, y Blais y Boyer, 1996; Best y Hubbard, 1999; Yawn y Beatty, 2000; Lledó, 2001; Benoit et al., 2004; Garrido y Sierra, 2013).

De esta forma, diversos autores (Lanoue, 1992; Jamieson y Adasiewicz, 2000; Yawn y Beatty, 2000; Garrido y Sierra, 2015) consideran que la función principal que cumplen los debates electorales, desde el punto de vista de la decisión del voto, es, además de un mayor conocimiento de los candidatos, la de refuerzo de las preferencias del electorado, al margen de la incidencia o impacto que puedan tener sobre el ciudadano indeciso. En cualquier caso, aunque el único efecto observable sea el refuerzo, éste puede tener consecuencias en los resultados electorales al convertir previas inclinaciones provisionales en votos definitivos que, en ausencia de los debates, podrían no haberse cristalizado, manifestándose en forma de abstención.

Algunos autores han señalado que la causa de la disparidad de los resultados empíricos de las investigaciones es el contexto en el que se desarrollan las campañas electorales. Así, el escenario más propicio para que las campañas electorales $\mathrm{y}$, por ende, los debates electorales, tengan efectos significativos sobre el voto de los ciudadanos es el de unas elecciones reñidas, en las que no haya una fuerte fidelización del electorado y, por tanto, buena parte de los ciudadanos se encuentran indecisos. Así, cuanto más reñidas sean las elecciones y mayor el porcentaje de indecisos, mayor será el efecto que podrán ocasionar los debates. Desde nuestro punto de vista, la competitividad de las elecciones no es el único factor decisivo, sino que los elementos constitutivos del propio debate también tienen cierto peso en los efectos, sin que los diversos factores ostenten ninguna jerarquía, conviviendo en temporalidad e importancia.

En este contexto, los debates electorales pueden ser decisivos como consecuencia de la generación de la percepción de cuál de los candidatos ha resultado más y menos convincente. Esta percepción acerca de quién ha salido más beneficiado y perjudicado del debate se debe, por un lado, a que, en los debates, los candidatos hacen un esfuerzo por diferenciarse del resto, ya que los ciudadanos toman la decisión de apoyar a uno u otro candidato a través de un juicio comparativo, por lo que no tendrían razones para preferir a uno u otro líder si pareciesen lo mismo (Isolatus, 2011); y, por otro lado, a que la cobertura mediática tiende a expresarse empleado términos deportivos (lucha, ganador, perdedor) $\mathrm{y}$, de esta forma, la percepción del candidato como ganador puede suponer el aumento de su valoración que, en última instancia, puede inclinar el voto de los indecisos en uno u otro sentido. Además, habitualmente los debates tienen lugar en los días próximos a las elecciones y los ciudadanos pueden no recordar todo lo que los participantes dicen, pero pueden recordar quien ha sido el ganador y el perdedor, de modo que los indecisos podrían basar su decisión en esta oportunidad de conseguir información sobre los políticos y sus propuestas $\mathrm{y}$, por consiguiente, votar al candidato que perciben como ganador (Schrott, 1990). 
Asimismo, Lledó (2001) afirma que la percepción del ganador de los debates se encuentra fuertemente influenciada por las actitudes y preferencias preexistentes, como la valoración del líder, la identificación partidista o la intención de voto, entre otras; o lo que es lo mismo, la agregación de preferencias previas actuaría como una barrera al considerar ganador al candidato del partido contrario al que se señala en la intención de voto, por lo que, en todo caso, los espectadores optarían por el empate. Cada elector, en función de la "percepción selectiva", tiende a considerar como ganador al candidato que representa al partido político por el que siente una mayor simpatía y, por ende, aquel candidato que se corresponda con la organización política preferida para una mayor masa de electores, que muestre unas predisposiciones claras antes de las elecciones, será el que figure como ganador del debate electoral en los resultados de las encuestas.

No obstante, los estudios que analizan el impacto del ganador en el voto son prácticamente inexistentes. Abramowitz (1978), en su trabajo sobre el efecto de los debates presidenciales estadounidenses de 1976, encuentra evidencias del efecto de persuasión sobre la racionalidad de las decisiones de voto, de modo que, los votantes adoptarían las posiciones ante los distintos temas de sus candidatos preferidos; McLeod et al. (1979) identifican algún impacto de varias variables relacionadas con los debates sobre las preferencias presidenciales de los votantes, de forma que los encuestados que veían a Carter como el ganador del debate, mostraban una mayor implicación en las campañas y un mayor grado de afinidad con el Partido demócrata, además de observar cambios en las preferencias de voto hacia este político; pero es Schrott (1990) el que demuestra que al seleccionar a un candidato como el ganador de los debates, los votantes de las elecciones de la Alemania del este de 1976, 1980, 1982 y 1983, evaluaban a ese político de manera más positiva y a sus oponentes de forma más negativa, aumentando la probabilidad de votar al partido del candidato ganador.

Con relación a la influencia de los debates en la imagen del candidato, Popkin et al. (1994) muestran que las actitudes hacia los candidatos incumbent son más estables que las actitudes hacia los challengers. Yawn y Beatty (2000) señalan la existencia de aspectos específicos de la actuación de los candidatos que produce un cambio de opinión. Nimmo y Savage (1976) sostienen que estas dimensiones se refieren a los roles políticos y estilísticos proyectados por los candidatos al gobierno, incluyendo el rol político a aquellos actos de un candidato que están particularmente relacionados con su posición y aspiración a ser un líder político; mientras que el rol estilístico englobaría a las actuaciones de un candidato que no son directamente políticas, al problema en el cual actúa para impresionar a los votantes con sus capacidades, y a la exhibición de las cualidades personales. Por su parte, Kinder et al. (1980) argumentan que los votantes conciben el prototipo de presidente en términos de personalidad y actuación. Este presidente ficticio debería exhibir rasgos personales como la honestidad, el afecto y el valor, y su actitud debería caracterizarse por rasgos como el liderazgo, la diplomacia y las habilidades para solucionar los problemas. Pero los autores argumentan que más importante que esto, es la competencia y la verdad. De acuerdo con Martel (1983), estos rasgos han sido particularmente importantes en determinadas estrategias de debate.

Nuestra investigación, tratará de comprobar si estos planteamientos de investigaciones precedentes son extensibles a los debates de las Elecciones Generales de abril de 2019, partiendo de la premisa de que la influencia de los debates en el comportamiento electoral es limitada.

\subsection{Los debates en la campaña de las Elecciones Generales de abril 2019: Un partido de ida y vuelta}

La celebración de los debates durante el transcurso de la campaña electoral de las Elecciones Generales del 28 de abril de 2019 no ha estado exenta de polémica. Tras un primer intento de 
organizar un debate a cinco, entre los candidatos del PSOE, PP, Unidas Podemos, C's y Vox, la Junta electoral impide su celebración, argumentando el incumplimiento del principio de proporcionalidad y aceptando, así, los recursos interpuestos por Esquerra Republicana de Cataluña (ERC), el Partido Nacionalista Vasco (PNV) y Coalición Canaria (CC). RTVE decide entonces fijar la fecha del debate para el martes 23 de abril, la misma fecha prevista para el debate de Atresmedia, en lugar del lunes 22, como estaba previsto inicialmente.

Ante la coincidencia de ambos debates, Pedro Sánchez, quien en un principio había descartado su participación en el debate de RTVE, pero sí había aceptado la invitación de la compañía privada, alegando que en este debate estaría presente el líder de Vox, anuncia que acudirá al debate de la corporación pública. Contrariamente, Pablo Casado y Albert Rivera rechazan la proposición de RTVE, dado que ya se habían comprometido con Atresmedia, mientras que Pablo Iglesias pide que se modifique la fecha, como finalmente acontece.

Así, tras esta controversia, el primero de los debates electorales a cuatro, organizado por RTVE, entre los principales candidatos a la Presidencia del Gobierno: Pedro Sánchez (PSOE), Pablo Casado (PP), Pablo Iglesias (Unidas Podemos) y Albert Rivera (C's) tuvo lugar el pasado 22 de abril, seis días antes de la celebración de las Elecciones Generales, en el Estudio A1 de Prado del Rey en Madrid. El debate, moderado por el periodista Xavier Fortes y emitido en directo por La 1, 24h, RNE, RTVE.es, además de por TVE internacional y Radio Exterior para llegar a los millones de españoles residentes en el extranjero, contó con una duración total de 1 hora y 26 minutos, dividida en cuatro bloques temáticos: Política económica, fiscal y empleo, Política social, estado de bienestar, pensiones e igualdad, Política territorial; y Regeneración democrática y pactos electorales, estableciéndose por sorteo quien abriría y cerraría cada bloque. De acuerdo con las normas del debate, cada uno de los candidatos dispondría de cuatro minutos y medio por bloque, de los cuales, un minuto y medio, en el que no se podrían interrumpir, se debería dedicar a la exposición del programa, mientras que los otros tres minutos, se deberían dedicar al propio debate, en el sentido de la contraposición de medidas y de la realización de ataques y respuestas entre los cuatro candidatos; además de una intervención inicial de un minuto y del conocido como "minuto de oro", el mensaje final en el que los candidatos piden expresamente el voto para el partido político al que representan.

Finalmente, el segundo de los debates electorales entre los mismos líderes políticos, organizado por el grupo de comunicación Atresmedia y moderado por los periodistas Ana Pastor y Vicente Vallés, se emitió el 23 de abril, también en prime time, a través de los canales Antena 3, La Sexta, Onda Cero, Atresplayer y el canal internacional, con una duración de 2 horas y 5 minutos. Como consecuencia de su celebración al día siguiente del debate de RTVE, el de Antena 3 fue interpretado por los medios de comunicación en términos deportivos, como la "vuelta" del debate de RTVE, siendo denominado por los propios organizadores como "El debate decisivo".

Si bien este debate también está articulado en bloques temáticos, en este caso, tres: Programas electorales, Modelo territorial/Cataluña y Pactos, se diferencia de su predecesor en que no dispondría de tiempos, y en que los moderadores tendrían la posibilidad de realizar preguntas directas durante en el transcurso del debate, además de una ronda rápida para iniciarlo, terminando, como suele ser lo habitual, con el minuto de oro.

\section{Metodología y datos}

Con la finalidad de averiguar, en primer lugar, si los debates producen algún efecto en las percepciones de los ciudadanos acerca de los líderes políticos o de su decisión de voto $\mathrm{y}$, en segundo lugar, si los debates suponen efectivamente un elemento condicionante del voto a los principales partidos (Partido 
Popular (PP), Partidos Socialista Obrero Español (PSOE), Ciudadanos (C's) y Unidas Podemos (UP)) en las pasadas Elecciones Generales de abril de 2019, se lleva a cabo un análisis inicial desde una perspectiva descriptiva, antesala de un modelo de regresión lineal generalizado con función link logit para explicar el voto a cada una de las formaciones políticas. Para nuestra investigación, hemos empleado el Estudio n ${ }^{\circ} 3248^{1}$ Postelectoral Elecciones Generales, 2019 elaborado por el Centro de Investigaciones Sociológicas (CIS). Dicho estudio cuenta con una batería de preguntas relativas a los debates electorales, que el CIS ha utilizado ya en numerosos estudios previos.

Para nuestro análisis hemos seleccionado las variables más relevantes, algunas de las cuales ha sido necesario recodificar. A continuación, se relacionan:

- Voto a partido: Variable categórica dicotómica, donde la categoría 1 representa el voto al partido de interés y la categoría 0 representa el voto al resto de partidos, el voto blanco o nulo y la abstención. Variable que se ha utilizado como variable dependiente en el modelo logit.

- Sexo: Variable categórica dicotómica, donde la categoría 1 representa a los hombres y la categoría 0 representa a las mujeres.

- Edad: Variable continua que recoge la edad de los encuestados.

- Nivel de estudios: Variable ordinal, tratada como continua, con cinco categorías, donde la categoría 1 representa a los encuestados con algunos años de estudios primarios, la categoría 2 representa a los encuestados con estudios primarios, la categoría 3 representa a los encuestados con estudios secundarios, la categoría 4 representa a los encuestados con un grado FP (Formación Profesional), y la categoría 5 representa a los encuestados con estudios universitarios.

- Situación laboral: Variable categórica con cuatro categorías, donde la categoría 1 representa a los activos remunerados, es decir, a los trabajadores; la categoría 2 representa a los pasivos remunerados, es decir, a los jubilados y pensionistas; la categoría 3 representa a activos no remunerados, es decir, a los parados; y la categoría 4 representa a los pasivos no remunerados, es decir, a los estudiantes y amas de casa.

- Autoubicación ideológica: Variable continua que recoge las puntuaciones en las que se sitúan los encuestados a sí mismos en una escala de 1 a 10, donde 1 es la posición más a la izquierda y 10 es la posición más a la derecha.

- Simpatía: Variable categórica dicotómica, donde la categoría 1 representa sentir simpatía o cercanía hacia el partido de interés y la categoría 0 representa sentir simpatía o cercanía hacia alguno de los demás partidos.

- Candidato más convincente: Variable categórica dicotómica, donde la categoría 1 representa al candidato más convincente, en opinión de los encuestados, en los debates electorales en cuestión y la categoría 0 representa al resto de candidatos.

\section{Resultados}

Los debates electorales son considerados los eventos estrella de las campañas electorales (Sierra, 2012; Carrera, 2015; García, 2015), no sólo por suponer una oportunidad propicia para el contraste de las distintas posiciones y de las diversas medidas propuestas por los candidatos a la presidencia en unas elecciones, sino también por su gran alcance. Prueba de ello son los elevados índices de audiencia que se registran tras la emisión de cada uno de estos programas. El debate de RTVE tuvo 8.886.000 espectadores de media (el 43,8\% de cuota de pantalla), lo que significa que el 31,1\% de la población vio, al menos, un minuto del debate, alcanzando en el minuto de oro los 9.629 .000 espectadores $(48,7 \%)$. Por

\footnotetext{
${ }^{1}$ El Estudio CIS no 3248 Postelectoral Elecciones Generales, 2019 fue realizado entre el 10 y el 15 de mayo de 2019 a una muestra total de 5.943 individuos, seleccionados mediante un procedimiento de muestreo polietápico, estratificado por conglomerados, siendo el error muestral, para un nivel de confianza del 95,5\% (dos sigmas) y, para el conjunto de la muestra y en el supuesto de muestreo aleatorio simple.
} 
su parte, el debate de Atresmedia consiguió todavía mayores niveles de audiencia: 9.447.000 espectadores (de media) siguieron el debate (el 48,7\% de share), lo que implica que el 37,9\% de la población vio, al menos, un minuto del debate, superando en el minuto de oro los diez millones de espectadores (10.963.000 espectadores, es decir, el 51,6\% de share) (Barlovento, 2019a, 2019b).

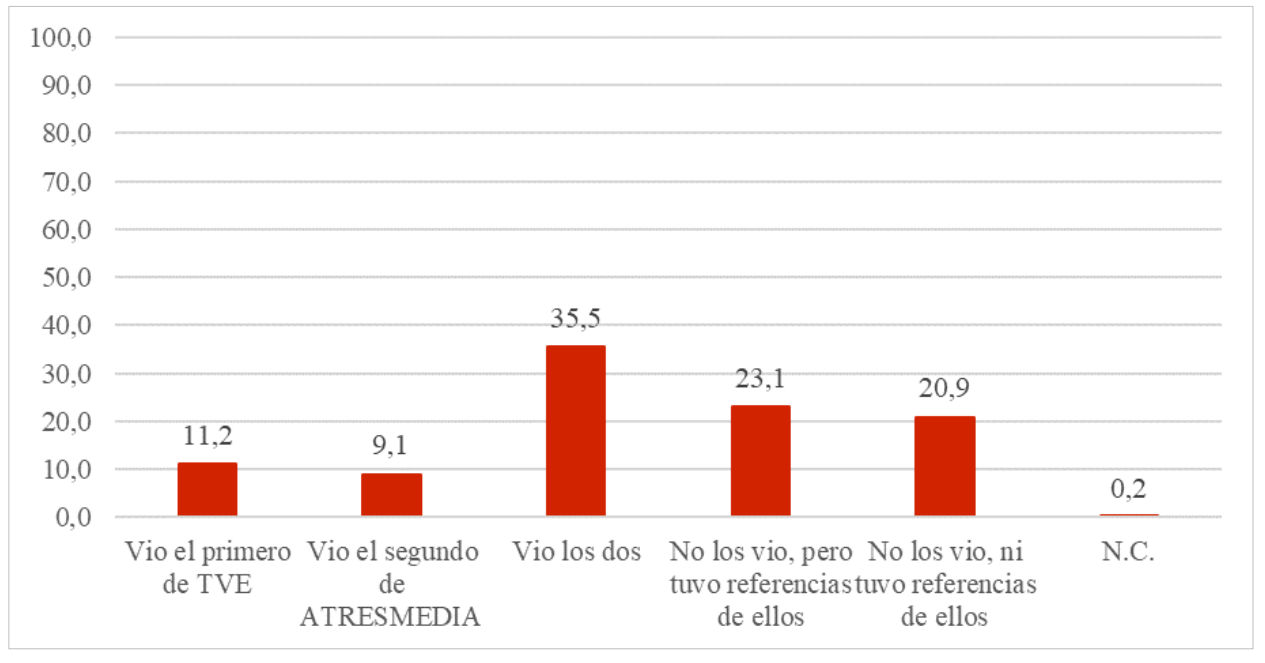

Gráfico 1. Seguimiento de los debates.

Fuente: elaboración propia a partir de los datos del Estudio CIS N 3247 Postelectoral Elecciones Generales 2019.

En consonancia con los datos oficiales de audiencias, los datos de la encuesta postelectoral del CIS confirman el gran alcance los debates electorales. El 35,5\% de la población vio ambos debates, y en torno a un $10 \%$ vio alguno de ellos (el 11,2\% vio el de RTVE y el 9,1\%, el de Atresmedia). El 23,1\% de los ciudadanos, aunque no los vio, afirman haber tenido referencias de ellos (gráfico 1).

Además, del 55,8\% de los encuestados que afirman haber visto los dos debates o alguno de ellos, la mayoría vio los dos enteros (34\%) o los dos debates en parte $(26,4 \%)$, si bien, el 9,9\% de los entrevistados vio el de RTVE entero y el $11,7 \%$ en parte, y el 6,8\% vio el de Atresmedia entero y el $10,1 \%$ en parte (gráfico 2).

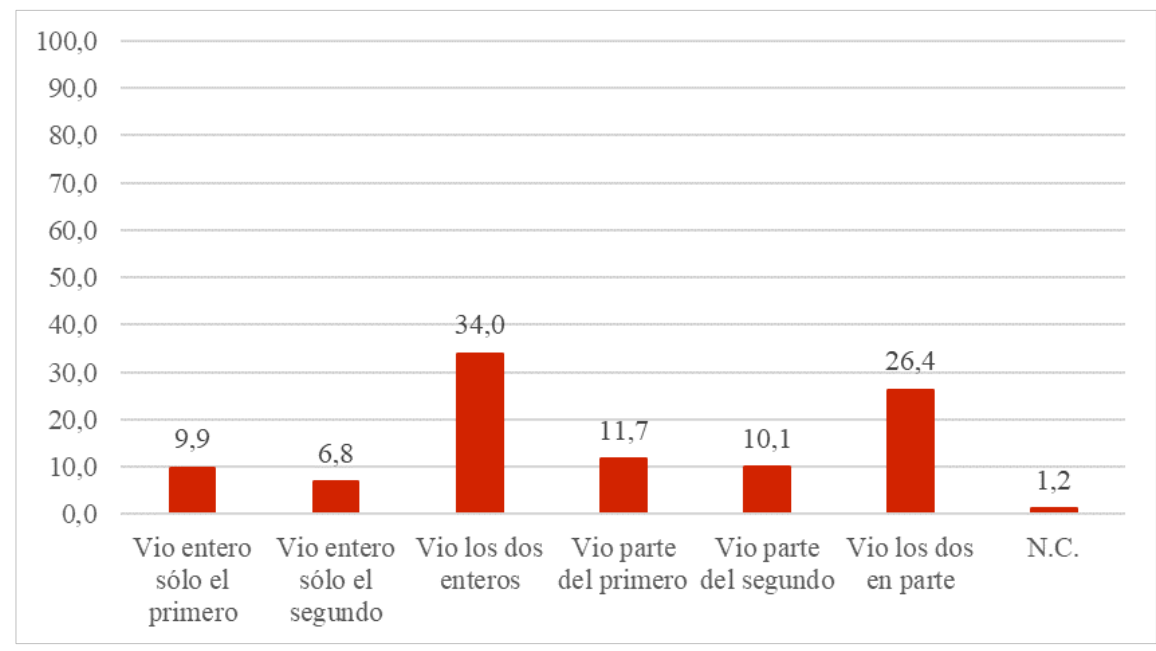

Gráfico 2. Tipo de seguimiento de los debates.

Fuente: elaboración propia a partir de los datos del Estudio CIS No 3247 Postelectoral Elecciones Generales 2019. 
En cuanto a cuál de los cuatro candidatos que se presentaron a ambos debates resultó ser el más convincente (gráfico 3), la gran mayoría de los espectadores consideran que fue Pablo Iglesias (34,7\%), encontrándose muy por debajo Pedro Sánchez y Albert Rivera (más de un 15\% y de un $18 \%$ de los encuestados opina que resultó ser más convincente Pablo Iglesias que Pedro Sánchez y Albert Rivera, respectivamente), pero, sobre todo, Pablo Casado, ya que sólo un 5,6\% de los ciudadanos que vieron los debates considera que ha sido el candidato más convincente en estos eventos televisivos.

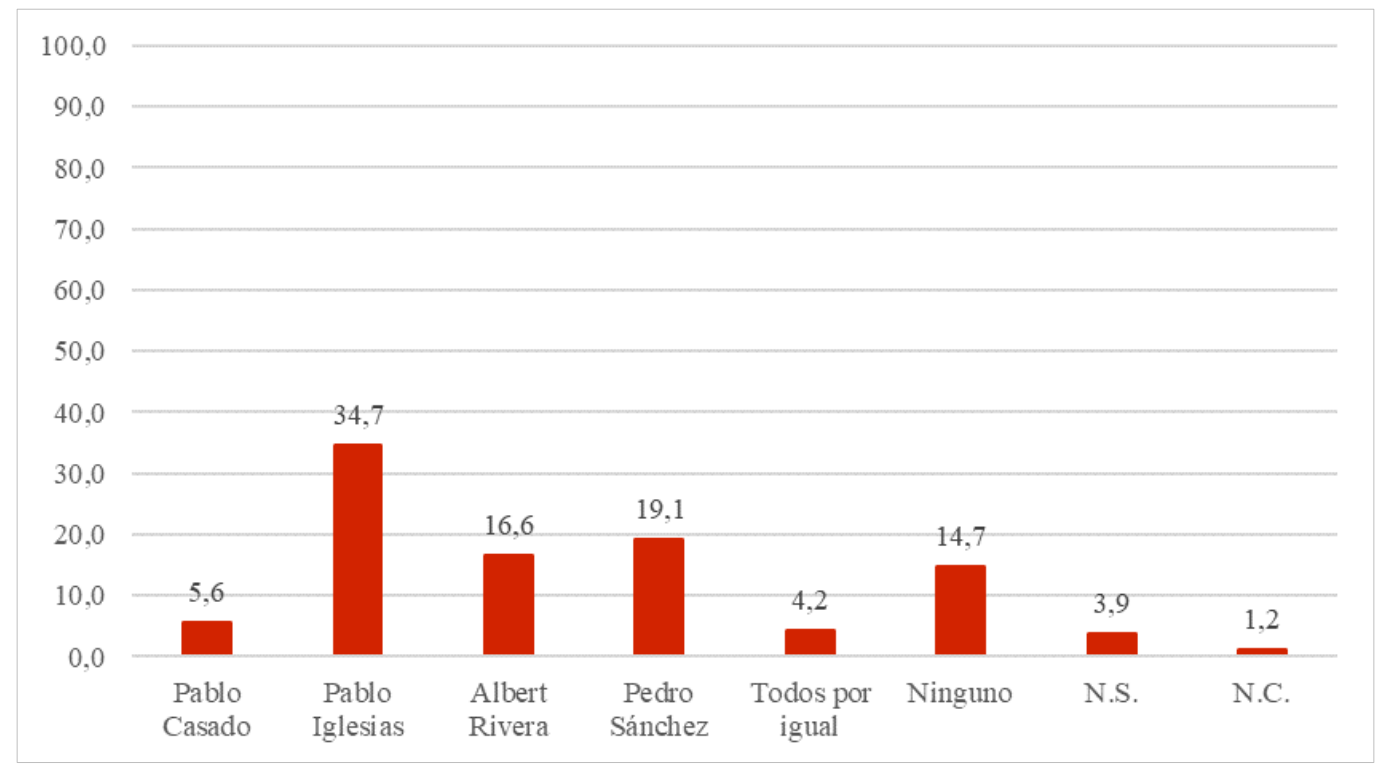

Gráfico 3. Candidato más convincente.

Fuente: elaboración propia a partir de los datos del Estudio CIS No 3247 Postelectoral Elecciones Generales 2019.

No obstante, no sólo la percepción del candidato como ganador se relaciona con una mayor valoración del mismo (tabla 1), como recoge la literatura, sino que, además, el simple hecho de ser espectador de los debates electorales (en contraste con quien no los han visto), independientemente de las predisposiciones políticas de los ciudadanos, está relacionado con una mejor valoración de los líderes políticos (tabla 2).

Como se observa en la tabla 2, por tanto, parece que el público de los debates electorales de abril de 2019 valora mejor a los candidatos que aquellos que no los vieron, aunque también podría ser el caso de que ven los debates porque valoran mejor a los candidatos que los que no los ven. De cualquier modo, la relación entra ambas variables se confirma mediante la aplicación del test de KolmogorovSmirnov de homogeneidad de manera unilateral a grupos de dos poblaciones, en este caso, a los espectadores del debate y a los no espectadores del debate. Atendiendo a los resultados del test, para los niveles de significación normalmente establecidos (y, cuando se compara a los encuestados que han visto los debates con quienes no los han visto, no sólo se encuentran diferencias significativas entre ambos grupos, sino que las valoraciones de todos y cada uno de los líderes políticos que han participado en ambos debates electorales son mejores si los entrevistados han visto dichos programas en contraposición a quienes no los han visto. 
Tabla 1. Comparación de la Valoración de los líderes políticos con la Valoración de los líderes políticos por Candidato más convincente.

\begin{tabular}{|c|c|c|}
\hline & $\begin{array}{c}\text { Valoración } \\
\text { líderes políticos }\end{array}$ & $\begin{array}{l}\text { Valoración } \\
\text { líderes por } \\
\text { Candidato más } \\
\text { convincente }\end{array}$ \\
\hline Pablo Casado & 3,55 & 7,28 \\
\hline Pablo Iglesias & 4,11 & 6,41 \\
\hline Albert Rivera & 4,18 & 6,95 \\
\hline Pedro Sánchez & 5,05 & 7,50 \\
\hline
\end{tabular}

Fuente: elaboración propia a partir de los datos del Estudio CIS No 3247 Postelectoral Elecciones Generales 2019.

Tabla 2. Valoración de los líderes politicos por Visionado de los debates.

\begin{tabular}{|c|c|c|c|c|c|}
\hline \multirow{2}{*}{\multicolumn{2}{|c|}{ Visionado de los debates }} & \multicolumn{4}{|c|}{ Valoración de los líderes políticos } \\
\hline & & \multirow{2}{*}{$\begin{array}{c}\begin{array}{c}\text { Pablo } \\
\text { Casado }\end{array} \\
3,63\end{array}$} & \multirow{2}{*}{$\begin{array}{c}\begin{array}{c}\text { Pablo } \\
\text { Iglesias }\end{array} \\
4,52\end{array}$} & \multirow{2}{*}{$\begin{array}{c}\text { Albert } \\
\text { Rivera }\end{array}$} & \multirow{2}{*}{$\begin{array}{c}\begin{array}{c}\text { Pedro } \\
\text { Sánchez }\end{array} \\
5,34\end{array}$} \\
\hline \multirow{3}{*}{ Vio los debates } & Media & & & & \\
\hline & $\mathbf{N}$ & 3105 & 3139 & 3137 & 3172 \\
\hline & Desv. típica & 2,466 & 2,639 & 2,474 & 2,500 \\
\hline \multirow{3}{*}{ No vio los debates } & Media & 3,44 & 3,51 & 3,89 & 4,72 \\
\hline & $\mathbf{N}$ & 2029 & 2134 & 2080 & 2199 \\
\hline & Desv. típica & 2,472 & 2,448 & 2,393 & 2,615 \\
\hline \multirow{3}{*}{ Total } & Media & 3,55 & 4,11 & 4,18 & 5,09 \\
\hline & $\mathbf{N}$ & 5134 & 5273 & 5217 & 5371 \\
\hline & Desv. típica & 2,470 & 2,611 & 2,453 & 2,565 \\
\hline \multirow{2}{*}{$\begin{array}{l}\text { Test Kolmogov- } \\
\text { Smirnov }\end{array}$} & $\begin{array}{l}\text { Valor del } \\
\text { estadístico }\end{array}$ & 0,0682 & 0,1710 & 0,1066 & 0,0783 \\
\hline & $p$-valor & $1,106 \times 10^{-}$ & $2,2 \times 16$ & $\underset{13}{1,524 \times 10^{-}}$ & $2,188 \times 10^{-7}$ \\
\hline
\end{tabular}

Fuente: elaboración propia a partir de los datos del Estudio CIS N 3247 Postelectoral Elecciones Generales 2019.

Como ya se ha visto, en la literatura existente suele haber cierto consenso en torno a la idea de que los ciudadanos opinarán que el candidato más convincente es aquel que represente al partido por el que sienten más cercanía o es más próximo a sus ideas y, del mismo modo, por el que tienen pensando votar en las elecciones (Lledó, 2001). Sin embargo, en las Elecciones Generales de abril de 2019, esta suposición no parece ser cierta en todos los casos (tablas 3 y 4), aunque sí para la mayoría de los entrevistados. E1 91,7\% de los electores que declaran sentir simpatía por Unidas Podemos y el $86,9 \%$ de los que finalmente votaron a esta confluencia política consideran que el candidato más convincente fue Pablo Iglesias, pero además el 30,2\% de los que afirmar sentirse próximos al PSOE y el $32,6 \%$ de sus votantes también lo piensan. Por otra parte, además del $42,4 \%$ de los ciudadanos que manifiestan sentir simpatía hacia el PP y el 34,7\% de los votantes de este partido político que consideran que Pablo Casado fue el candidato más convincente, también lo opinan el 23,2\% de los que se sienten cercanos a Vox y el $17,8 \%$ de los que lo votaron. Finalmente, del $68,1 \%$ de los simpatizantes de C's y del $61,5 \%$ de sus votantes que declaran que Albert Rivera fue el candidato más convincente, así también lo manifiestan el 25,9\% de los entrevistados que se sienten cercanos al PP y el 22,4\% de los votantes de este partido, y el $42,7 \%$ de los que se sienten próximos a Vox y el 
$40,2 \%$ de sus votantes (a este respeto, recordemos que Vox no disponía de un representante propio en el debate).

Tabla 3. Candidato más convincente por Partido por el que siente más cercanía o es más próximo a sus ideas.

\begin{tabular}{|c|c|c|c|c|c|c|c|c|c|c|c|c|c|}
\hline & & \multicolumn{11}{|c|}{ Partido por el que siente más cercanía o es más próximo a sus ideas } & \multirow[b]{2}{*}{ Total } \\
\hline & & $\mathbf{P P}$ & PSOE & $C^{\prime} s$ & $\begin{array}{c}\text { Unidas } \\
\text { Podemos }\end{array}$ & $\begin{array}{c}\text { En } \\
\text { Comú } \\
\text { Podem }\end{array}$ & Vox & ERC & JxCat & $\begin{array}{l}\text { EAJ- } \\
\text { PNV }\end{array}$ & $\begin{array}{c}\text { EH } \\
\text { Bildu }\end{array}$ & Otro & \\
\hline \multirow{6}{*}{$\begin{array}{l}\text { Candidato más } \\
\text { convincente en el } \\
\text { debate electoral } \\
\text { televisado de las } \\
\text { elecciones } \\
\text { generales de } \\
2019\end{array}$} & Pablo Casado & $42,4 \%$ & $0,2 \%$ & $3,7 \%$ & $0,3 \%$ & & $23,2 \%$ & $1,2 \%$ & & & & & $7,4 \%$ \\
\hline & Pablo Iglesias & $5,4 \%$ & $30,8 \%$ & $12,2 \%$ & $91,7 \%$ & $82,4 \%$ & $9,8 \%$ & $60,5 \%$ & $65,4 \%$ & $45,5 \%$ & $65,0 \%$ & $67,1 \%$ & $39,7 \%$ \\
\hline & Albert Rivera & $25,9 \%$ & $4,3 \%$ & $68,1 \%$ & $0,7 \%$ & & $42,7 \%$ & $1,2 \%$ & & $4,5 \%$ & & $5,1 \%$ & $15,3 \%$ \\
\hline & Pedro Sánchez & $4,0 \%$ & $54,9 \%$ & $3,7 \%$ & $4,1 \%$ & $5,9 \%$ & $1,2 \%$ & $19,8 \%$ & $7,7 \%$ & $45,5 \%$ & $5,0 \%$ & $8,9 \%$ & $24,9 \%$ \\
\hline & Todos por igual & $4,9 \%$ & $1,9 \%$ & $2,7 \%$ & $1,0 \%$ & & $3,7 \%$ & $2,3 \%$ & $3,8 \%$ & & & $1,3 \%$ & $2,3 \%$ \\
\hline & Ninguno & $17,4 \%$ & $8,0 \%$ & $9,6 \%$ & $2,1 \%$ & $11,8 \%$ & $19,5 \%$ & $15,1 \%$ & $23,1 \%$ & $4,5 \%$ & $30,0 \%$ & $17,7 \%$ & $10,3 \%$ \\
\hline Total & & $100,0 \%$ & $100,0 \%$ & $100,0 \%$ & $100,0 \%$ & $100,0 \%$ & $100,0 \%$ & $100,0 \%$ & $100,0 \%$ & $100,0 \%$ & $100,0 \%$ & $100,0 \%$ & $100,0 \%$ \\
\hline
\end{tabular}

Fuente: elaboración propia a partir de los datos del Estudio CIS N 3247 Postelectoral Elecciones Generales 2019.

Tabla 4. Candidato más convincente por Recuerdo de Voto en las Elecciones Generales 2019.

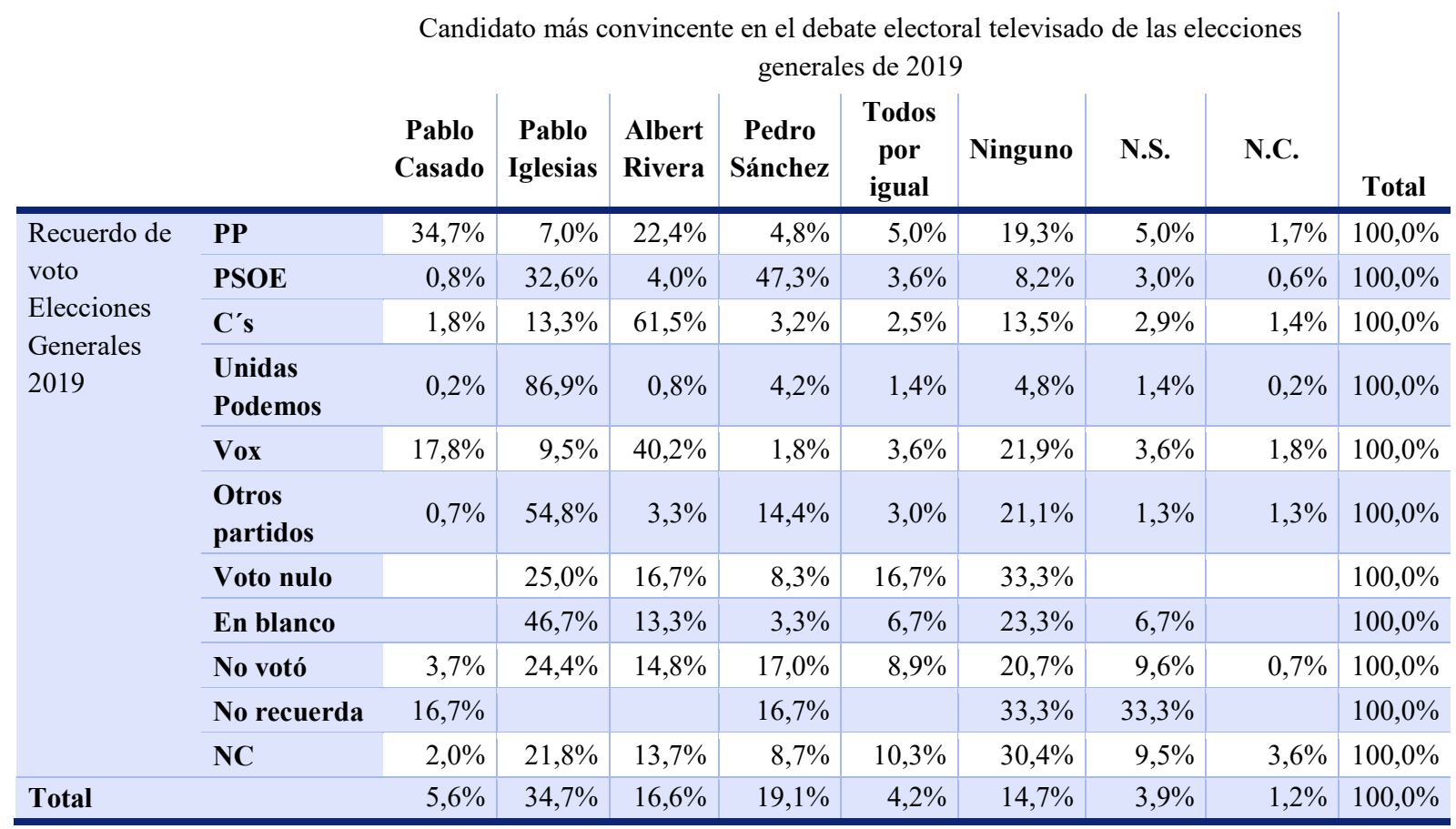

Fuente: elaboración propia a partir de los datos del Estudio CIS N 3247 Postelectoral Elecciones Generales 2019.

En definitiva, además de que la mayoría de los entrevistados consideran como el ganador de los debates electorales al líder del partido por el que sienten simpatía o por el que votaron en las elecciones, un importante porcentaje, sin embargo, perciben que el ganador puede ser el candidato de un partido que no es al que se sienten más próximos o por el que finalmente no votan, pero, en 
general, se trata del cabeza de lista de un partido localizado en el mismo bloque ideológico. Es decir, los votantes pueden valorar mejor la actuación del candidato de un partido al que no se sientan muy cercanos o por el que decidan no votar, pero tratándose este desplazamiento de un movimiento intra bloques.

A juicio de Benoit (2007a), los candidatos deben desalentar a los propios simpatizantes del partido a desertar o a votar por su oponente, tentar a los espectadores que se sientan próximos a los partidos rivales a desertar y a atraer a los candidatos de partidos independientes o de terceros partidos. Como el propio Xavier Fortes explica en el debate electoral de RTVE:

"Estamos en un escenario electoral muy abierto y ustedes (dirigiéndose a los candidatos partícipes en el debate) tienen que mirar, no sólo para la parroquia, sino también para los indecisos”.

Indecisos que, según los datos del Estudio n 3242 Macrobarómetro de marzo de 2019. Preelectoral Elecciones Generales 2019 del CIS, suponían, en aquel momento, el 41,6\% del electorado.

Al observar, de manera descriptiva, si los debates han causado algún tipo de efecto sobre la decisión de voto de los electores, podemos constatar, de acuerdo con la literatura, que el refuerzo es el principal efecto que producen los debates electorales, pues el $92,7 \%$ de los espectadores afirma que el visionado de los debates no ha cambiado su intención de voto. Si bien, un nada despreciable 7,1\% de los televidentes afirma que sí produjeron un cambio en su intención de voto, lo que supondría una diferencia notable respecto a las cifras que habitualmente se estiman en la mayor parte de la literatura anglosajona, entre el 1 y el 4\% (Jamieson y Adasiewicz, 2000).

Del 7,1\% de los entrevistados que afirman que los debates electorales han modificado su decisión de voto, en más de la mitad de los ciudadanos $(51,1 \%)$, los debates han tenido un efecto de conversión, es decir, los electores finalmente han votado por un partido por el que no tenían pensando votar antes del visionado de los debates. Este es un dato muy relevante ya que la conversión supone el efecto más traumático para los votantes, pues el cambio de voto supone un mayor esfuerzo para el electorado que su activación o desactivación (i Coma, 2008). No obstante, el 12,7\% de los encuestados reconoce que pensaba no votar y que finalmente votó, es decir, los debates han provocado un mayor efecto de activación que de desactivación, pues únicamente el 2,5\% de los entrevistados sostienen que los debates le desanimaron a la hora de acudir a las urnas.

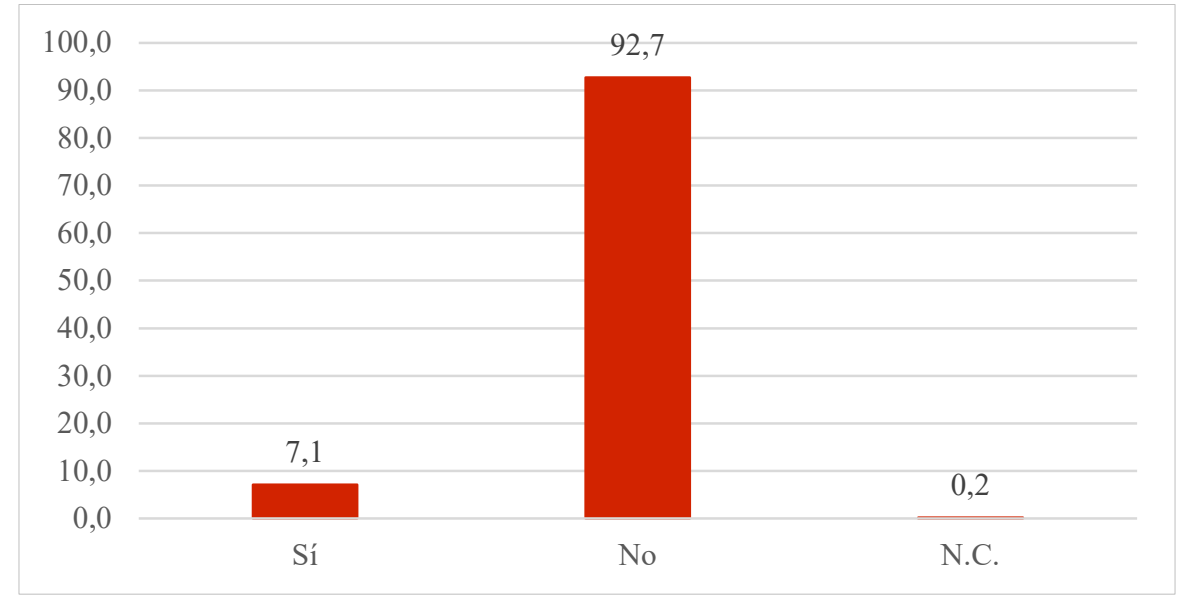

Gráfico 4. Cambio de intención de voto tras los debates.

Fuente: elaboración propia a partir de los datos del Estudio CIS N 3247 Postelectoral Elecciones Generales 2019. 


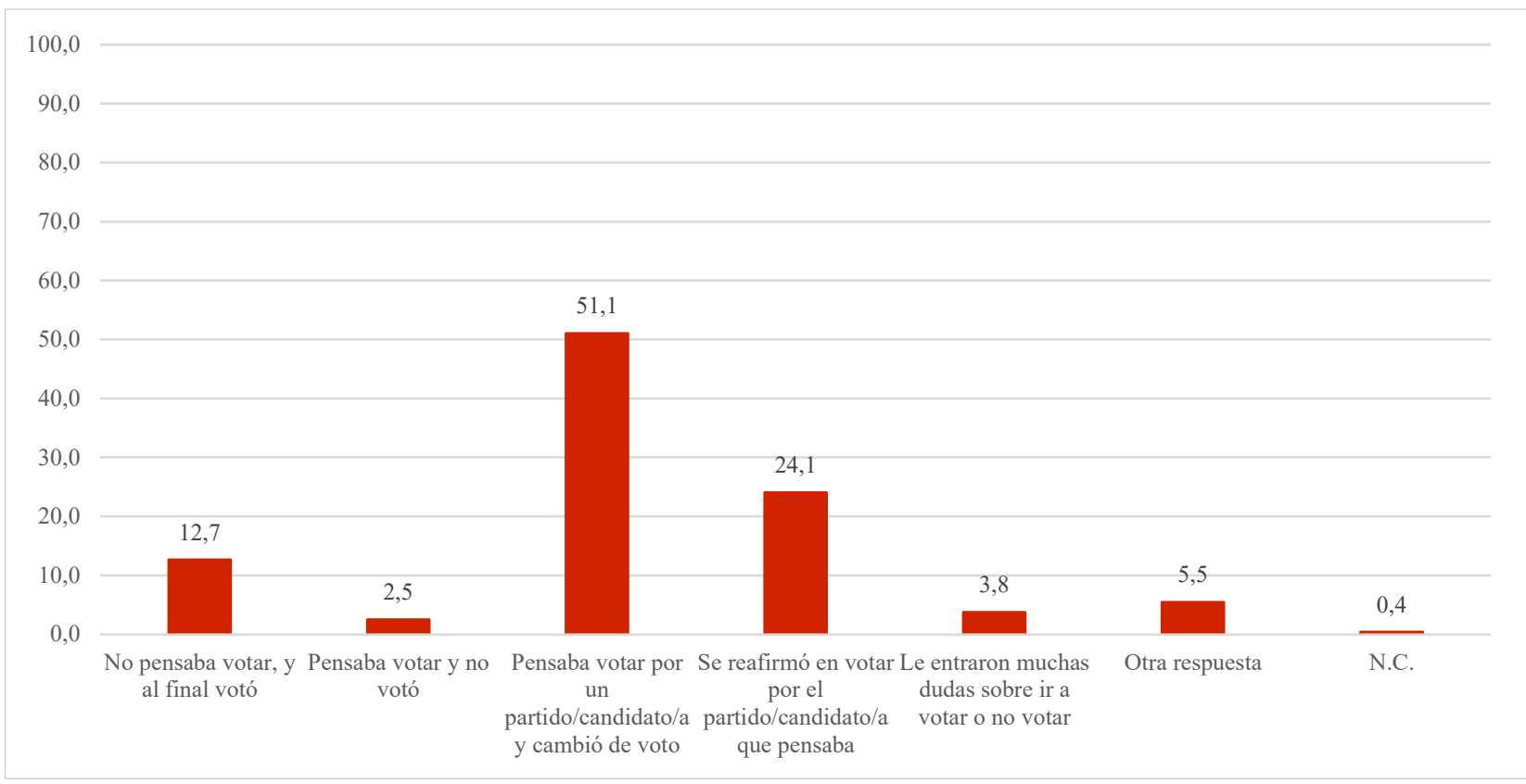

Gráfico 5. Sentido en el que cambió su voto tras los debates.

Fuente: elaboración propia a partir de los datos del Estudio CIS N 3247 Postelectoral Elecciones Generales 2019.

Conocidos los efectos que el visionado de los debates han causado en el comportamiento político de los ciudadanos, con el objetivo de corroborar si los debates electorales son un elemento condicionante del voto a los principales partidos en las Elecciones Generales de abril de 2019, a continuación, se presenta un modelo para el voto a cada uno de los principales partidos: PP, PSOE, $C^{\prime}$ 's y Unidas Podemos (tabla $5^{2}$ ), en los que se han introducido inicialmente, como factores explicativos, las variables: sexo (aunque esta no ha resultado significativa para ningún modelo); edad, la cual sólo ha resultado significativa para el caso del PP; el nivel de estudios, que no resulta significativa ni para el PP ni para el PSOE; la situación laboral, que no resulta significativa para ninguna de las cuatro formaciones políticas analizadas; la autoubicación ideológica, que no resulta significativa para $\mathrm{C}^{\prime} \mathrm{s}$; la simpatía o cercanía al partido político en cuestión $\mathrm{y}$, como variable representativa de los debates electorales, el candidato más convincente en dichos eventos televisivos.

Comenzando por el modelo de voto para el PP, resultan significativas, para un nivel de significatividad, la edad, la autoubicación ideológica, la simpatía hacia este partido político y el hecho de que Pablo Casado resultase ser el candidato más convincente en los debates electorales. De modo que, la odds ${ }^{3}$ de votar al PP se incrementa 1,022 veces por cada año que aumenta la edad del individuo; se incrementa 1,606 veces a medida que el encuestado se sitúa en una posición más a la derecha en la escala de autoubicación ideológica; y aumenta 179,733 y 2,969 veces cuando un ciudadano declara sentir simpatía por el PP y afirma que Pablo Casado fue el candidato más convincente en los debates electorales, respectivamente.

\footnotetext{
${ }^{2}$ En la tabla 5 se muestran los coeficientes Beta junto con los errores típicos y el nivel de significatividad representado a través de asteriscos, de modo que: $* p<0,05, * * p<0,01, * * * p<0,001$, pero en el texto se comentan los coeficientes Beta estandarizados.

${ }^{3}$ La odds representa el cociente fruto de la relación existente entre la probabilidad de éxito del evento y la probabilidad de fracaso del mismo, en este caso, el hecho de votar al partido político en cuestión.
} 
El modelo lineal generalizado para el caso del PSOE, nos revela que el voto hacia este partido político se explica a través de la autoubicación ideológica, la simpatía hacia esta organización política y el hecho de que Pedro Sánchez resultase ser el candidato más convincente en los debates. Así, la odds de votar al PSOE aumenta 0,749 veces a medida que el individuo se sitúa en una posición más a la izquierda en la escala de autoubicación ideológica; se incrementa 285,110 cada una de las veces que un ciudadano declara sentirse más próximo al PSOE, y aumenta 4,244 veces por cada votante que considera que Pedro Sánchez fue el candidato más convincente en las contiendas televisivas.

En cuanto a C's, su voto no se explica a través de la autoubicación ideológica, pero sí mediante el nivel de estudios de los encuestados y, nuevamente, por el hecho de sentir simpatía hacia este partido político y por considerar a Albert Rivera como el candidato más convincente. De esta forma, la odds de votar a C's se incrementa 1,333 veces a medida que aumenta el nivel de estudios del electorado, y se incrementa 325,330 y 14,265 veces por cada ciudadano que declara sentir simparía por esta organización política y que opina que Albert Rivera fue el candidato más convincente en los debates electorales, respectivamente.

Por último, el voto a Unidas Podemos se explica mediante las variables nivel de estudios, autoubicación ideológica y por el hecho de sentirse próximo hacia esta confluencia política y de considerar a Pablo Iglesias el candidato más convincente en los debates. Al igual que en el caso de C's, la odds de votar a Unidas Podemos se incrementa 1,283 veces a medida que aumenta el nivel de estudios de los encuestados, además de incrementarse 0,558 veces a medida que los ciudadanos se sitúan en una posición más a la izquierda en la escala de autoubicación ideológica, y 129,735 y 4,467 veces por cada votante que declara sentir simparía por Unidas Podemos y por cada elector que percibe a Pablo Iglesias como el candidato más convincente en los debates electorales, respectivamente.

Tabla 5. Modelos de voto.

\begin{tabular}{|c|c|c|c|c|}
\hline & PP & PSOE & $C^{\prime} s$ & $\begin{array}{l}\text { Unidas } \\
\text { Podemos }\end{array}$ \\
\hline Intercepto & $\begin{array}{c}-8,184 * * * \\
(0,915)\end{array}$ & $\begin{array}{c}-2,376 * * * \\
(0,309)\end{array}$ & $\begin{array}{c}-6,272 * * * \\
(0,664)\end{array}$ & $\begin{array}{c}-3,410 * * * \\
(0,609)\end{array}$ \\
\hline Edad & $\begin{array}{l}0,021^{*} \\
(0,010)\end{array}$ & & & \\
\hline Nivel de estudios & & & $\begin{array}{l}0,287^{*} \\
(0,122)\end{array}$ & $\begin{array}{c}0,249 * * \\
(0,096)\end{array}$ \\
\hline $\begin{array}{l}\text { Autoubicación } \\
\text { ideológica }\end{array}$ & $\begin{array}{c}0,474 * * * \\
(0,104)\end{array}$ & $\begin{array}{c}-0,290 * * * \\
(0,078)\end{array}$ & & $\begin{array}{c}-0,583 * * * \\
(0,105)\end{array}$ \\
\hline Simpatía & $\begin{array}{c}5,191 * * * \\
(0,373)\end{array}$ & $\begin{array}{c}5,653 * * * \\
(0,253)\end{array}$ & $\begin{array}{c}5,785 * * * \\
(0,361)\end{array}$ & $\begin{array}{c}4,865^{* * *} \\
(0,276)\end{array}$ \\
\hline $\begin{array}{l}\text { Candidato más } \\
\text { convincente }\end{array}$ & $\begin{array}{l}1,088^{*} \\
(0,430)\end{array}$ & $\begin{array}{c}1,445 * * * \\
(0,299)\end{array}$ & $\begin{array}{c}2,658 * * * \\
(0,363)\end{array}$ & $\begin{array}{c}1,497 * * * \\
(0,309)\end{array}$ \\
\hline $\begin{array}{l}\text { R cuadrado de } \\
\text { Nagelkerke }\end{array}$ & $83,6 \%$ & $86,0 \%$ & $81,5 \%$ & $80,9 \%$ \\
\hline
\end{tabular}

Fuente: elaboración propia a partir de los datos del Estudio CIS No 3247 Postelectoral Elecciones Generales 2019. 


\section{Discusión y conclusiones}

Tras la salida adelante de la moción de censura al gobierno de Mariano Rajoy interpuesta por el PSOE y la imposibilidad de la aprobación de los presupuestos, Pedro Sánchez convoca elecciones anticipadas para el 28 de abril de 2019, con la amenaza de la irrupción de Vox, un partido de extrema derecha, en el Congreso de los Diputados. En este contexto, se celebra la campaña electoral, dentro de la cual, tienen lugar dos debates electorales a cuatro entre los principales candidatos a la Presidencia del gobierno.

A pesar del carácter excepcional de estos comicios, no se podrían adjetivar de reñidos, pues atendiendo a los sondeos preelectorales publicados por distintos medios, parecía evidente que el PSOE ganaría las elecciones, quedando en segunda posición el PP. La única duda posible era que finalmente se produjese el sorpasso de C's a Unidas Podemos, tal y como apuntaban la mayoría de las encuestas. Situación que no incentivaría que las campañas electorales y, por ende, los debates electorales, tuviesen efectos determinantes en la orientación del voto de los ciudadanos.

A tenor de los resultados obtenidos en los modelos de voto a los principales partidos, podríamos afirmar, en primer lugar, que las variables sociodemográficas que, para la Escuela de Columbia, definían la orientación del voto de los ciudadanos, tienen una escasa influencia en la explicación del voto de las Elecciones Generales de abril de 2019, pues únicamente la edad sigue siendo un factor constitutivo del voto al PP, incrementándose la probabilidad de votar a este partido político a medida que aumenta la edad del individuo; y el nivel de estudios resulta un factor explicativo para los casos de las nuevas formaciones políticas: C's y Unidas Podemos, de tal forma que a medida que aumenta el nivel de estudios de los encuestados, se incrementa la probabilidad de votar a ambos partidos, lo cual podría deberse a que aquellas personas más formadas serían las que estarían más dispuestas a informarse acerca de los nuevos actores que han irrumpido en el panorama político.

En segundo lugar, los componentes psicológicos del voto definidos por la Escuela de Michigan siguen gozando de un considerable peso en la explicación del voto. De hecho, la simpatía, término con el que definimos el sentimiento de cercanía o de proximidad a las ideas de un partido político, es la variable con más poder explicativo del voto a los cuatro partidos analizados, como viene siendo habitual en la mayoría de modelos de comportamiento electoral; y la autoubicación ideológica también resulta un factor determinante de la orientación del voto para los casos del PP, el PSOE y Unidas Podemos en el sentido esperado, es decir, la probabilidad de votar al PP, aumenta a medida que los ciudadanos se sitúan más a la derecha y la probabilidad de votar al PSOE o a Unidas Podemos, se incrementa a medida que los individuos se sitúan en posiciones más a la izquierda en la escala de autoubicación ideológica. No obstante, resulta cuanto menos resaltable el hecho de que la autoubicación ideológica no resulte una variable significativa para explicar el voto a $\mathrm{C}^{\prime} \mathrm{s}$, quizás por el afán, en aquel momento, de los dirigentes de este partido político por situar a la formación naranja en el centro del espectro ideológico, dando una imagen de partido bisagra que podría pactar con derecha e izquierda.

Por último, la inclusión de los debates electorales en los modelos de voto se ha efectuado a través de la variable relativa al candidato más convincente, puesto que el simple visionado de los debates, con respecto a aquellos ciudadanos que no han sido espectadores de estos, no resulta significativo a la hora de explicar el voto a los partidos cuyos representantes participaron en estos eventos televisivos. A este respecto, también resulta resaltable el hecho de que, al introducir la variable valoración de los líderes políticos, la variable del candidato más convincente dejase de ser significativa y esto, sólo puede entenderse como que la actuación de los candidatos en los debates electorales supone un elemento constitutivo y de refuerzo de los propios liderazgos, afirmación que se confirma cuando 
observábamos que las valoraciones de los líderes aumentan significativamente cuando los ciudadanos han sido espectadores de los debates en contraposición a los que no lo han sido.

Por tanto, lo verdaderamente relevante, no es únicamente que las valoraciones de los líderes se incrementen como consecuencia del visionado de los debates, sino el hecho de que, en los cuatro modelos de voto, para los cuatro partidos, la identificación del líder como el candidato más convincente en el debate, supone un aumento de la probabilidad de votar al partido político en cuestión. Es decir, parece claro que los debates y la lectura que los ciudadanos hacen de los mismos tienen un efecto directo en el comportamiento electoral de aquellos que los ven, independientemente del efecto, ampliamente demostrado, de otras variables políticas clásicas, como la simpatía o la autoubicación ideológica.

Por ello, aunque los debates electorales supongan un riesgo para la imagen de los líderes políticos y los consiguientes resultados electorales, la no asistencia a un debate electoral puede tener unas consecuencias todavía más perjudiciales para los liderazgos que el hecho de recibir ataques por parte de los rivales políticos. Quizás, este efecto ha sido observado por los asesores de Mariano Rajoy tras las Elecciones Generales de 2015, pues al previo debate a cuatro le sustituyó Soraya Sáenz de Santamaría, mientras que sí decidió acudir al debate a cuatro anterior a las Elecciones Generales de 2016.

Aunque este estudio viene a confirmar el modelo de efectos limitados, según el cual, las campañas electorales tienen un efecto mínimo en el resultado de las elecciones y, por ende, los debates electorales no tendrían algún tipo de efecto más allá del refuerzo de las predisposiciones de los votantes; también pone de manifiesto la transformación que supone el paso de un sistema bipartidista a un sistema multipartidista más allá de sus consecuencias en los resultados electorales y la posterior conformación de gobierno, al hacer visible el cambio que supone en las percepciones de los espectadores de los debates acerca del candidato que resulta más convincente, en el sentido de que ya no se identifica a dicho candidato como el representante del partido político por el que los ciudadanos sienten más simpatía o al que finalmente votan, sino que la consideración de que un candidato sea el más convincente puede no deberse a las predisposiciones políticas o al acto más genuino del comportamiento político: el voto, siempre y cuando el líder político sea el representante de una formación política que se encuentre en el mismo bloque ideológico.

\section{Referencias bibliográficas}

Abramowitz, A. I. (1978). The Impact of a Presidential Debate on Voter Rationality. American Journal of Political Science, (22), 680-680. http://doi.org/10.2307/2110467

Barreiro, X. L., Pereira, M. y García, G. (2015). Los efectos sobre el voto de la campaña electoral en las elecciones europeas de 2014 en España. Revista Española de Ciencia Política, (39), 67-93.

Benoit, W. L. \& Wells, W.T. (1996). Candidates in conflict: Persuasive attack and defense in the 1992 presidential debates. University of Alabama Press.

Benoit, W. L. \& Harthcock, A. (1999). Functions of Great Debates: Acclaims, Attacks, and Defenses in the 1960 Presidential Debates. Communication Monographs, 66(4), 341-357. http://doi.org/10.1080/03637759909376484

Benoit, W. L., McKinney, M. S. \& Holbert, R. L. (2001). Beyond Learning and Persona: Extending the Scope of Presidential Debate Effects. Communication Monograph, 68(3), 259-273. http://doi.org/10.1080/03637750128060 
Benoit, W. L. \& Brazeal, L. M. (2002). A Functional Analysis of the 1988 Bush-Dukakis Presidential Debates. Argumentary and Advocacy, 38(4), 219-233.

http://doi.org/10.1080/00028533.2002.11821569

Benoit, W. L., Hansen, G. \& Verser, R. (2003). A Meta-Analysis of the Effects of Viewing U.S. Presidential Debates. Comunication Monographs, 70(4), 355-350. http://doi.org/10.1080/0363775032000179133

Benoit, W. L., Hansen, G. \& Verser, R. (2004). Presidential Debate Watching, Issue Knowledge, Character Evaluation, and Vote Choice. Human Communication Research, 30(1), 335-350. http://doi.org/10.1111/j.1468-2958.2004.tb00727.x

Benoit, W. L. (2007). Communication in Political Campaigns. Peter Lang.

Best, S. J. \& Hubbard, C. (1999). Maximizing Minimal Effects: The Impact of Early Primary Season Debates on Voter Preferences. American Politics Quarterly, 27(4), 450-467. http://doi.org/10.1177/1532673X99027004004

Bishop, G. F., Meadow, R. G. \& Jackson-Beeck, M. (Eds.) (1978). The Presidential Debates. Praeguer.

Blais, A. \& Boyer, M. (1996). Assesing the Impact of Televised Debates: The Case of the 1988 Canadian Election. Bristish Journal of Political Science, (26), 143-164. http://doi.org/10.1017/S0007123400000405

Carrera, V. (2015). La red de confianza de los debates electorales y la mente de los candidatos. Revista Marco, (1), 39-61.

Castro, P., Maneiro, E. y Peso, A. (2017). Análisis de los debates electorales: el procés como master frame. En J. M. Rivera, J. Montabes y N. Lagares (Eds.), Cataluña en proceso: las elecciones autonómicas de 2015, (pp. 213-235). Tirant lo Blanch.

Cho, J. \& Ha, Y. (2012). On the Communicative Underpinnings of Campaigns Effects: Presidential Debates, Citizen Communication, and Polarization in Evaluations of Candidates. Political Communication, 29(2), 184-2014. http://doi.org/10.1080/10584609.2012.671233

Crespo, I., Garrido, A., Riorda, M. \& Carletta, I. (2011). Manual de Comunicación Política y estrategias de campaña. Candidatos, medios y electorales en una nueva era. Biblios.

Downs, A. (1957). An Economic Theory of Democracy. John Wiley.

Gallego, M. y Bernárdez, A. (2017). Influencia y repercusión mediática de los debates "cara a cara" celebrados ante las elecciones generales de 2008 en España: José Luís Rodríguez Zapatero (PSOE) Vs. Mariano Rajoy (PP). Vivat Academia. Revista de Comunicación, (141), 139-154. http://doi.org/10.15178/va.2017.141.139-154

García, J. (2015). La cobertura mediática de los debates electorales en España. Revista Española de Ciencia Política, (38), 135-161. 
Garrido, A. y Sierra, J. (forthcoming). Los efectos de los debates electorales sobre la decisión de voto: Un estudio a través de las encuestas del CIS. Universidad de Murcia.

Geer, J. G. (1988). The Effects of Presidential Debates on the Electorate's Preferences for Candidates. American Political Quarterly, 16(4), 486-501.

http://doi.org/10.1177/004478088016004005

Herranz-Rubio, C. (2020). La producción científica sobre los debates electorales en España: Análisis bibliométrico (1993-2018). Revista Mediterránea de Comunicación/Mediterranean Journal of Communication, 11(1). http://doi.org/10.14198/MEDCOM2020.11.1.2

Herrero, J. C. y Benoit, W. L. (2009). Análisis funcional de los debates en las elecciones generales de 2008. Zer-Revista de Estudios de Comunicación, 14(27), 61-81.

Holbrook, T. M. (1994). The Behavioral Consequences of Vice-Presidential Debates: Does the Undercard Have any Punch? American Politics Quarterly, 22(4), 469-482. http://doi.org/10.1177/1532673X9402200404

Holbrook, T. M. (1996). Do Campaigns Matter? Sagei.

Coma, F. M. (2008). ¿Por qué importan las campañas electorales? CIS.

Informe Barlovento: Debate Electoral 22 Abril 2019.

Informe Barlovento: Debate Electoral 23 Abril 2019.

Isolatus, P. (2011). Analyzing Presidential Debates. Functional Theory and Finnish Political Communication Culture. Nordicom Review, 32(1), 31-43.

Jamieson, K. H. \& Adasiewicz, C. (2000). What can voters learn from election debates. En S. Coleman (Ed.). Televised election debates. International perspectives, (pp. 25-42). MacMillan.

Jamieson, K. H. \& Birdsell, D. S. (2000). Presidential Debates: The Challenge of Creating an Informed Electorate. Oxford, Reino Unido: Oxford University Press.

Kinder, D. R., Peters, M. D., Abelson, R. P. \& Fiske, S. T. (1980). Presidential Prototypes. Political Behavior, (2), 315-337.

Lledó, P. (2001). La influencia de los debates electorales sobre la decisión de voto: el caso de mayo de 1993. Revista Española de Ciencia Política, (5), 143-170.

Luengo, Ó. (2011). Debates electorales en televisión: una aproximación preliminar a sus efectos inmediatos. Revista Española de Ciencia Política, (25), 91-96.

Lanoue, J. D. (1992). One that Made a Difference. Cognitive, Consistency, Political, Knowledge, and the 1980 Presidential Debate. Public Opinion Quarterly, 56(2), 168-184. http://doi.org/10.1086/269309

Manin, B. (2006). Los principios del gobierno representativo. Alianza Editorial. 
Martel, M. (1983). Political Campaign Debates: Images, Strategies, and Tactics. Longman.

McLeod, J. M., Durall, J. A., Ziemke, D. A. \& Bybee, C. R. (1979). Reactions of Young and Older Voters: Expanding the Context of Effects. En: S. Kraus (Ed.). The Great Debates: Carter vs. Ford, 1976. Indiana University Press.

Nimmo, D. \& Savage, R. L. (1976). Candidates and their images: Concepts, Methods, and Findings. Goodyear.

Popkin, S. L. (1994). The Reasoning Voter. University of Chicago Press.

Shelley, M. C. \& Hwang, H. (1991). The Mass Media and Public Opinion Polls in the 1988 Presidential Election. Trends, Accuracy, Consistency and Events. American Political Quarterly, 19(1), 59-79. http://doi.org/10.1177/1532673X9101900104

Schrott, P. (1990). Electoral Consequences of Winning Debates. Public Opinion Quarterly, 54(4), 567-585. http://doi.org/10.1086/269228

Sierra, J. (2012). Planteamientos sobre los efectos de los debates electorales en televisión: aplicación al caso español. XXII World Congress of Politican Science. Madrid, España.

Weiler, M. (1989). The 1988 Electoral Debates and Debate Theory. Argumentation and Advocacy, 25(4), 214-219. http://doi.org/10.1080/00028533.1989.11951401

Yawn, M. \& Beatty, B. (2000). Debate-induced Opinion Change: What Matters? American Politics Quarterly, 28(2), 270-285. http://doi.org/10.1177/1532673X00028002007

\section{AUTORES:}

\section{Nieves Lagares Diez}

Profesora titular de Ciencia Política y de la Administración en la Universidad de Santiago de Compostela y experta en el estudio de la formación y organización de los partidos políticos, liderazgo y la mercadotecnia política. Entre sus publicaciones más recientes destacan los libros publicados junto con J. M. Rivera y J. Montabes en 2016, Cataluña en proceso: las elecciones autonómicas de 2015 (Valencia: Tirant lo Blanch); y junto con C. Ortega y P. Oñate en 2019, Las elecciones autonómicas de 2015 y 2016 (Madrid: CIS), y el artículo "Condiciones y razones del procés" con E. Jaráiz y X. L. Barreiro (2017), Aucaria, 19, 141-170.

mnieves.lagares@usc.es

Orcid ID: https://orcid.org/0000-0001-5304-0581

\section{Erika Jaráiz Gulías}

Doctora en Ciencia Política y profesora del Departamento Ciencia Política y Sociología de la USC desde el año 2008. Pertenece al Equipo de Investigaciones Políticas de la misma universidad, catalogado como Grupo de Referencia Competitiva por la Xunta de Galicia. Ha presentado numerosas comunicaciones en congresos nacionales e internacionales. Tiene experiencia en campañas electorales, y ha sido Gerente de la Mancomunidad del área Intermunicipal de Vigo (20072014) y Jefa de Gabinete de la Secretaría de Análisis y Proyección de la Presidencia de la Xunta de Galicia (2005-2007). Ha participado en numerosos contratos y proyectos de investigación, algunos de los cuales ha dirigido como investigadora principal, entre los que destacan la "Realización de una 
guía práctica de orientación para la realización de estudios de análisis de la demanda y de encuestas de satisfacción (2014)" y la elaboración del "Informe de Percepción Ciudadana: La calidad de los Servicios Públicos IX" (2014 y 2015)", ambos para la Agencia Española de Evaluación y Calidad de los Servicios (AEVAL). Imparte habitualmente clase en diversos Másters propios y oficiales entre los que destacan el Máster universitario en Marketing, Consultoría y Comunicación Política de la USC, de cuya Comisión Académica es Secretaria, y el Máster Universitario en Liderazgo y dirección pública (INAP), dónde además coordina el módulo de TFM. Además, ha recibido formación metodológica en a Essex Summer School in social Science Data Analysis and Collection y en la Universitat Pompeu Fabra, entre otras. Es Secretaria de Redacción de la Revista de Investigaciones Políticas y Sociológicas.

erika.jaraiz@usc.es

Orcid ID: https://orcid.org/0000-0003-2382-6713

\section{Paloma Castro Martínez}

Técnica superior de apoyo a la investigación en el Equipo de Investigaciones Políticas de la Universidad de Santiago de Compostela, catalogado como Grupo de Referencia Competitiva por la Xunta de Galicia. Actualmente, se encuentra realizando el programa de doctorado Marketing político, actores e instituciones en las sociedades contemporáneas de la misma universidad. Sus publicaciones más recientes son: "La protesta y el voto. ¿Cuánto hay de protesta en el voto a los nuevos partidos?", escrita en colaboración con María Pereira y Adrián García, para el libro Las elecciones autonómicas de 2015 y 2016 de N. Lagares, C. Ortega y P. Oñate (Eds.). Madrid. CIS, 2019; "Agenda mediática y agenda política", escrita con Antón Losada, y "Análisis de los debates electorales: el procés como master frame", junto con Elba Maneiro y Alejandro Peso, para el libro Cataluña en proceso, de J.M. Rivera, J. Montabes y N. Lagares (Eds.). Valencia. Tirant lo Blanch, 2017. Además, dispone de formación metodológica tras la realización del Máster en Técnicas Estadísticas de la Universidad de Santiago de Compostela.

paloma.castro2@usc.es

Orcid ID: https://orcid.org/0000-0001-9453-7770 